\title{
Age- and weight group-specific weight gain patterns in children and adolescents during the 15 years before and during the COVID-19 pandemic
}

\author{
Mandy Vogel iD ${ }^{1,2 凶}$, Mandy Geserick ${ }^{1,2}$, Ruth Gausche ${ }^{1,2}$, Christoph Beger (iD ${ }^{1,2}$, Tanja Poulain ${ }^{1,2}$, Christof Meigen ${ }^{1,2}$, Antje Körner (iD ${ }^{1,2}$, \\ Eberhard Keller ${ }^{1,2}$, Wieland Kiess ${ }^{1,2}$ and Roland Pfäffle ${ }^{1,2}$
}

(C) The Author(s) 2021

\begin{abstract}
BACKGROUND/OBJECTIVES: There is a concern that measures aiming to limit a further spread of COVID-19, e.g., school closures and social distancing, cause an aggravation of the childhood obesity epidemic. Therefore, we compared BMI trends during the 15 years before and during the COVID-19 pandemic.

SUBJECTS/METHODS: To assess the change in weight dynamics during the first months of COVID-19, we compared the trends of 3-month change in BMI-SDS ( $\triangle B M I-S D S)$ and the proportions of children showing a high positive (HPC) or high negative (HNC) weight change between 2005 and 2019 and the respective changes from 2019 (pre-pandemic) to 2020 (after the onset of antipandemic measures) in more than 150,000 children (9689 during the pandemic period). The period of 3 months corresponds approximately to the first lockdown period in Germany.

RESULTS: During the COVID-19 pandemic, we found a substantial weight gain across all weight and age groups, reflected by an increase in the 3-month change in BMI-SDS $(\beta=0.05, p<0.001)$, an increase in the proportion of children showing HPC (OR $=1.4$, $p<0.001)$, and a decrease in the proportion of children showing HNC $(\mathrm{OR}=0.7, p<0.001)$. Besides, we found the same trends since 2005 on a low but stable level with a yearly increase of $\triangle$ BMI-SDS by $\beta=0.001(p<0.001)$, the odds of HPC increased by OR high $\_$pos $=1.01(p<0.001)$, and the odds of HNC decreased by $\mathrm{OR}_{\text {high } \_ \text {neg }}=0.99(p<0.001)$. These rather small effects accumulated to $\beta=0.02, \mathrm{OR}_{\text {high_pos }}=1.14$, and $\mathrm{OR}_{\text {high_pos }}=0.85$ over the whole period $2005-2019$. Alarmingly, both the long-term and the shortterm effects were most pronounced in the obese subgroup.

CONCLUSIONS: There are positive dynamics in different measures of weight change, indicating a positive trend in weight gain patterns, especially within the group of children with obesity. These dynamics are likely to be escalated by COVID-19-related measures. Thus, they may lead to a significant further aggravation of the childhood obesity pandemic.

International Journal of Obesity (2022) 46:144-152; https://doi.org/10.1038/s41366-021-00968-2
\end{abstract}

\section{INTRODUCTION}

On March 11, 2020, the World Health Organization termed the COVID-19 outbreak a pandemic. Many countries have been affected and took measures to limit infection rates. Those measures included social distancing, home confinement, the closure of shops, sports and cultural facilities, and schools and nurseries. Children, although only mildly affected by the virus itself, experienced profound disruption of their daily lives. Besides adverse psychological effects like increased anxiety and loneliness $[1,2]$, different scientists worry about an increase in overweight and obesity caused by a decline in physical activity (PA), an increase in sedentary behavior (SB), and a change in dietary behavior [3, 4] associated with increased snacking [5] or higher consumption of ultra-processed food [6]. Indeed, several studies showed a decrease in PA accompanied by an increase in SB in children during the COVID-19-induced confinement [5-8]. Although studies indicated a lockdown-related weight gain in adults $[9,10]$, to our knowledge, there is no study examining the consequences of the COVID-19-induced behavioral changes on the weight status in a large population-based cohort of children and adolescents covering the whole age range from 1 to 18 years. However, monitoring children's weight status is of particular interest because childhood obesity is likely to persist into adulthood [11]. With 158,000,000 affected children, childhood obesity is a pandemic on its own [12]. It is related to many comorbidities like hypertension, impaired glucose metabolism, and even cancer [13] or depression [14]; an earlier onset is often related to more severe sequelae [14]. Moreover, in the context of COVID-19, obesity increases the likelihood of severe disease progression, even in children [13, 15].

Based on the weight trend pattern during school time and summer recess, a simulation study predicted an increase in mean BMI-SDS during COVID-19-induced school closures [16]. Other studies showed associations between an increase in overweight/

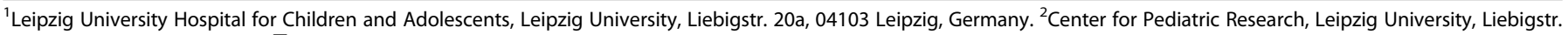
20a, 04103 Leipzig, Germany. ${ }^{\bowtie}$ email: mandy.vogel@medizin.uni-leipzig.de 
obesity prevalences and economic crises [17, 18] or natural disasters [19]. With more than 500,000,000 children affected by the COVID-19-induced measures [20], even minor effects can cause a tremendous aggravation of the childhood obesity pandemic. Therefore, our study compared the trends of BMI changes and proportions of high positive (HPC)/negative weight changes (HNC) from 2005 to 2019 with the respective changes from 2019 (pre-pandemic) to 2020 (after the onset of antipandemic measures) in a large pediatric cohort in Germany.

\section{SUBJECTS AND METHODS Participants and setting}

Data were retrieved from the CrescNet patient registry, a network of primary care pediatricians, endocrinological treatment centers, and clinics in Germany. It aims to monitor children's growth and development for clinical and scientific purposes [21]. All parents gave their informed consent. The data collection is supervised and monitored by the data protection officer of the Medical Faculty, University of Leipzig. CrescNet is registered with ClinicalTrials NCT03072537 as Growth Monitoring Network. Because this study used only retrospective collected data available to the researcher only anonymized, no additional IRB vote was necessary. Height and weight were measured at each visit by trained staff according to standardized procedures [21]. Data on age, sex, height, weight, and diagnoses from any consultation are pseudonymized and transferred to the $\mathrm{CrescNet}$ registry. The registry was approved by the Federal Saxonian Data Protection Authority and is registered at ClinicalTrials.gov (NCT03072537). All healthy children aged $\geq 1$ year with a height and weight measurement between September 2019 and February 2020 (t0) and a follow-up measurement between April and July 2020 (t1) were selected from the CrescNet database; the same selection process was done for the years 2005-2019. If children had more than one eligible pair of measurements per year, only the last one was used for analyses. Children with health conditions affecting weight or body composition were not selected. The CrescNet registry contains no information about acute conditions like infectious diseases. The list of excluded diagnoses is included in Supplementary Table 1. There are substantially fewer measurements in 2018-2020. For 2020, there are obvious reasons: (1) there is no baseline measurement between September and December 2020, which leads to fewer included visits/children. (2) There was a drop in visits registered within CrescNet, presumably associated with the COVID-19 and the related measures [22]. Similar effects were observed in different countries, and the suspected reasons are diverse [23, 24]. (3) There is also a delay between measurement and entry to the CrescNet database and the retrospective entry of measurements years after the measurement [21]. The drop from 2017 to 2018 is related to the newly introduced General Data Protection Regulation (legal binding to European law), imposing higher expenses on the participating practices.

\section{Measures}

According to the current German guidelines [25], BMI was calculated and transformed to standard deviation scores (BMI-SDS) using the references by Kromeyer-Hauschild [26]. For each year, the change of BMI-SDS between $\mathrm{t} 0$ and $\mathrm{t} 1$ was calculated as the standardized difference, i.e., the 3-month change in BMI-SDS ( $\triangle \mathrm{BMI}-\mathrm{SDS})$. Three monthly change rates were chosen because it corresponds to the duration of the first lockdown period in Germany. Classification into the following weight groups was based on BMI-SDS at t0: underweight (UW, <-1.28 BMI-SDS), normal weight (NW, $-1.28 \leq \mathrm{BMI}-\mathrm{SDS}<1.28$ ), overweight (OW, $1.28 \leq \mathrm{BMI}-\mathrm{SDS}<1.88$ ),

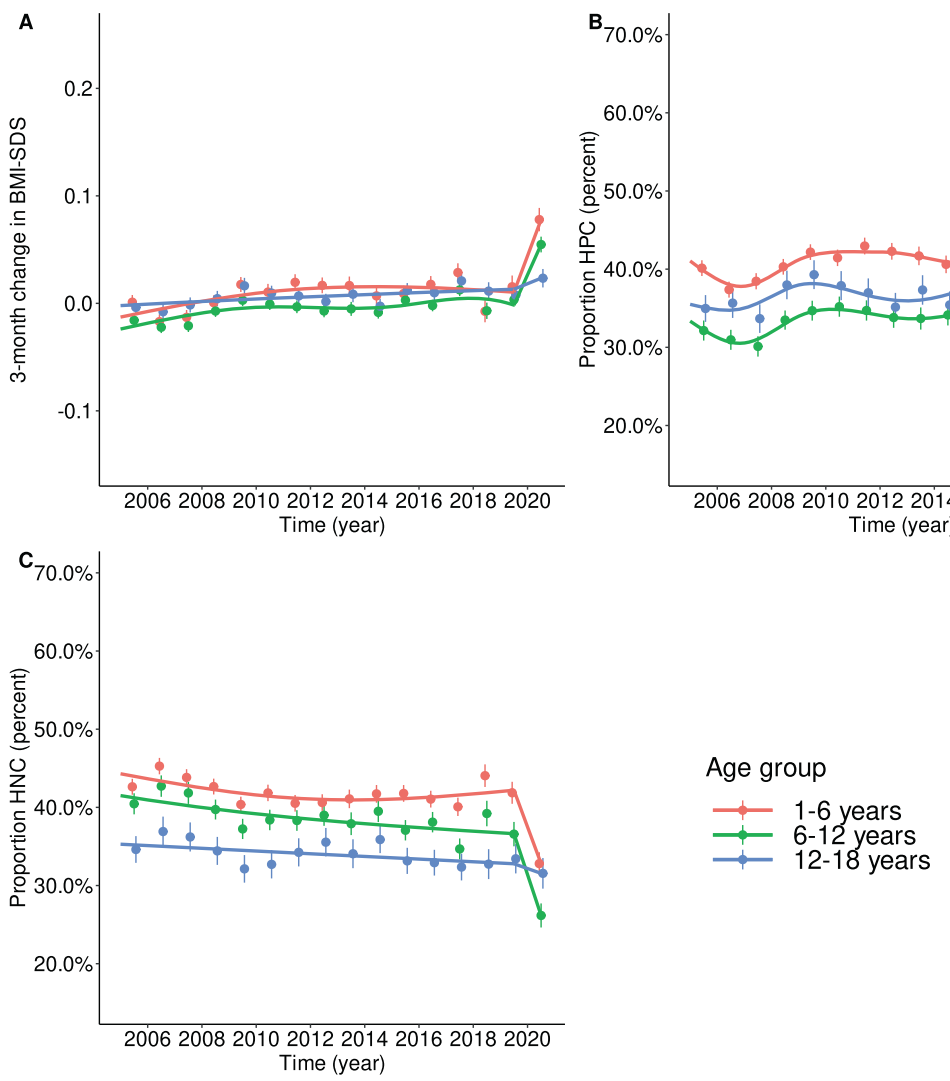

Fig. 1 Trends in $\triangle B M I-S D S$, HPC, and HNC between 2005 and 2019 modeled via linear additive mixed models by age group. A Trends in $\triangle$ BMI-SDS are shown as lines; points indicate yearly means $\pm 95 \%$ confidence levels. Between 2005 and 2019 (pre-pandemic), the trends were mainly stable, showing only a slight increase. From 2019 (prepandemic)to 2020 (after the onset of anti-pandemic measures), we found a substantial increase, less pronounced in the oldest age group. B The trends in the proportions of children with HPC show the same pattern as we found for $\triangle \mathrm{BMI}$-SDS. The patterns were also similar across the age groups but at higher levels for younger children. $\mathbf{C}$ Theinverse trends were found for the proportions of children with HNC. There was a small negative trend between 2005 and 2019. Between 2019 (prepandemic) and 2020, the proportions of children with HNC decreased substantially. The drop was less pronounced in the oldest age group. 


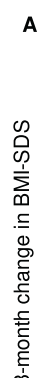

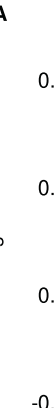

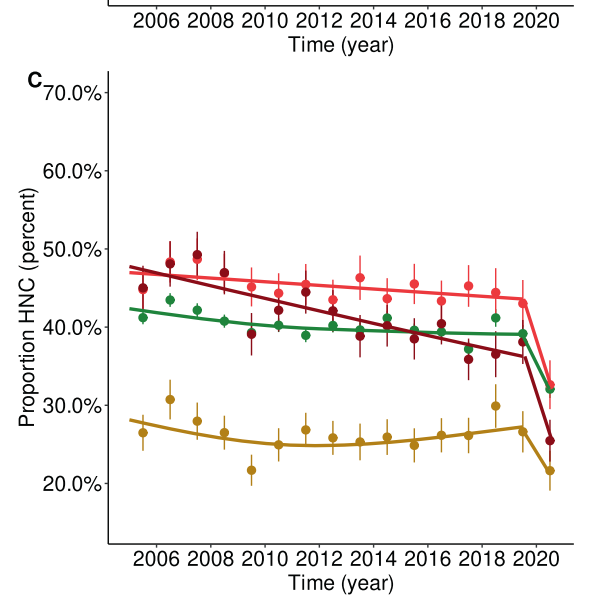

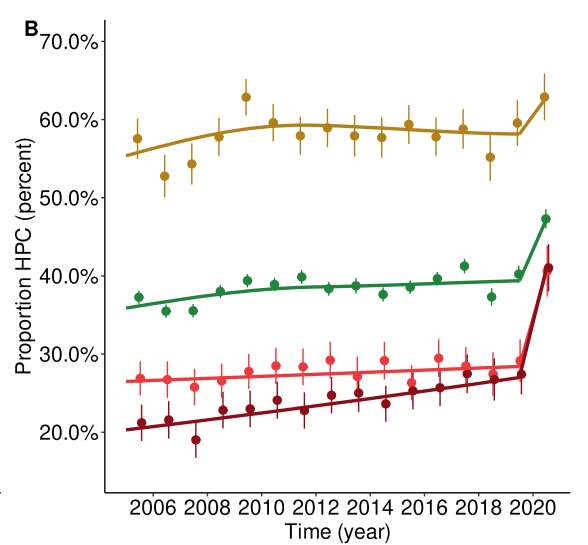

Weight group at to

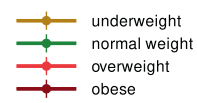

Fig. 2 Trends in $\triangle B M I-S D S$, HPC, and HNC between 2005 and 2019 modeled via linear additive mixed models by weight group. A Trends in $\triangle$ BMI-SDS are shown as lines; points indicate yearly means $\pm 95 \%$ confidence levels. Between 2005 and 2019 (pre-pandemic), the trends were mainly stable, showing only a slight increase. From 2019 (pre-pandemic) to 2020 (after the onset of anti-pandemic measures), we found a substantial increase for all weight groups. B The trends in the proportions of children with HPC show the same pattern as we found for $\triangle B M I-$ SDS. However, the increase between 2019 (pre-pandemic) and 2020 was substantially stronger for children already affected by overweight and obesity. C The inverse trends were found for the proportions of children with HNC. There was a small negative trend between 2005 and 2019 for the normal weight and overweight subgroups. The trend was substantially stronger in children with obesity. Between 2019 (prepandemic) and 2020, the proportions of children with HNC decreased substantially. Again, the drop was most pronounced in children already affected by overweight or obesity.

and obese $(\mathrm{OB}, \mathrm{BMI}-\mathrm{SDS} \geq 1.88)$ also according to the German guidelines [25]. Age at to was used to define three age groups: 1-6 years (nursery, preschool), 6-12 (primary school), and 12-18 (secondary school). According to Geserick et al., a change outside $\pm 0.2 \mathrm{BMI}-\mathrm{SDS}$ per year was classified as an HPC or an HNC, respectively [11].

\section{Statistical methods}

Descriptive statistics were given as mean (standard deviation) for continuous variables and counts (percentage) for categorical variables. To model the time trend of $\triangle B M I-S D S$, generalized additive mixed models (GAMM) were applied with $\triangle B M I-S D S$ as the outcome and the numeric equivalent of $\mathrm{t} 1$ (centered around 2010 for numerical reasons) as independent variable stratified by weight/age group. Cubic splines were used as smoothing terms. Accordingly, time trends of the proportions of HPC/HNC were estimated applying logistic GAMM. Subsequently, because for all age and weight groups the $\triangle \mathrm{BMI}-\mathrm{SDS}$ and the proportions of HPC/ HNC were relatively stable between 2005 and 2019 (Figs. 1 and 2), effects for the respective trends from 2015 to 2019 were estimated using (logistic) linear mixed regression models as was the change between 2019 and 2020. Results are presented as change/odds ratio (OR) per 1 year for the trends between 2005 and 2019, the respective cumulative effect from 2005 to 2019 , and as change/OR from 2019 to 2020 , including the $95 \%$ confidence interval $(95 \% \mathrm{Cl})$. Differences in trends between (a) weight groups, (b) age groups, and (c) boys and girls were examined. To adjust results for multiple measurements per subject, we included the respective random effects in the models. The confidence level was set to $a=0.05$. $P$ values and $\mathrm{Cls}$ were adjusted for multiple testing using a method controlling for family-wise error rates as described by Hothorn et al. [27]. All hypothesis tests were two-sided. All statistical analyses were performed using R, v.4.0 [28].

\section{RESULTS}

Data from 274,456 children were retrieved from the CrescNet registry. We excluded 94 measurements from 27 children because of an extreme BMI-SDS (outside the interval $[-5,5]$ ) and 173 measurements from 48 children because they had an extreme change rate $(\triangle \mathrm{BMI}-\mathrm{SDS}>2$ for children aged $\geq 3$ or $\triangle \mathrm{BMI}$-SDS $>3$ for children aged $<3$ years because smaller children have higher natural variability in BMI-SDS). We considered those extreme values to be likely due to severe organic disorders. Finally, 252,910 measurement pairs from 153,508 children were included in the analyses. The numbers of children included per year, weight, and age group are given in Supplementary Table 2. Basic descriptive statistics by year are given in Table 1 . Interestingly, trends in the 3-month change in BMI-SDS differed between age and weight groups but not between sexes (Supplementary Fig. 1). The same was true for percentages of HPC/HNC (Supplementary Figs. 2 and 3). Therefore, sex was not considered during further analyses. In general, the trends differed more between weight groups than between age groups (Figs. 1 and 2). We found no significant interaction between age and weight group. 


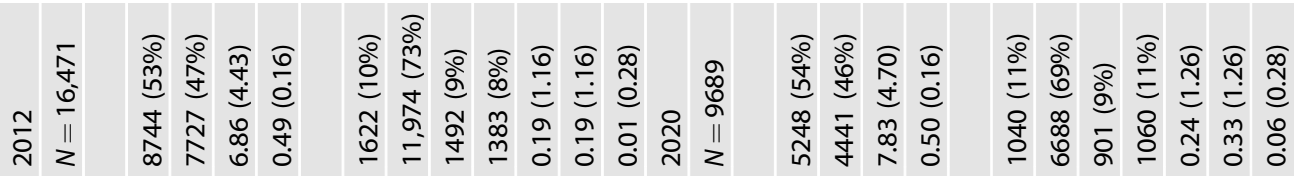

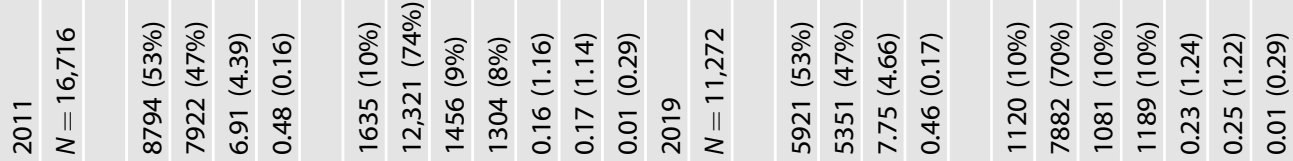

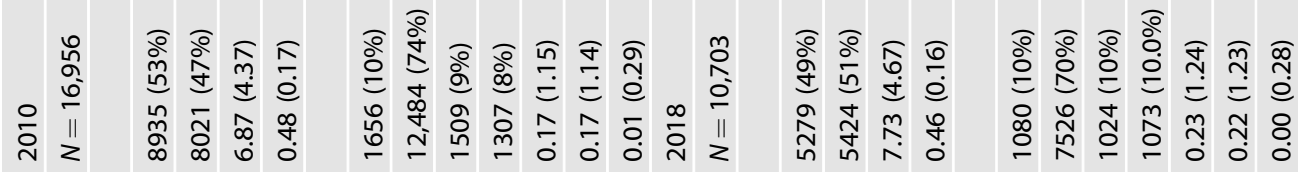

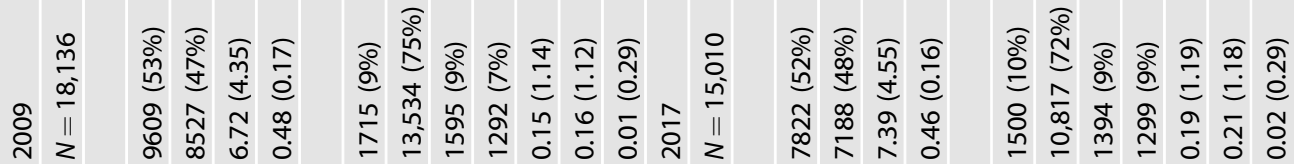

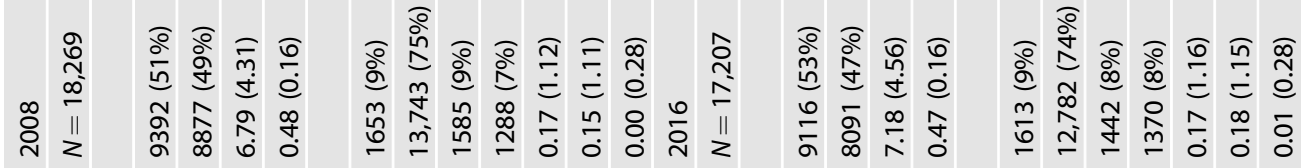

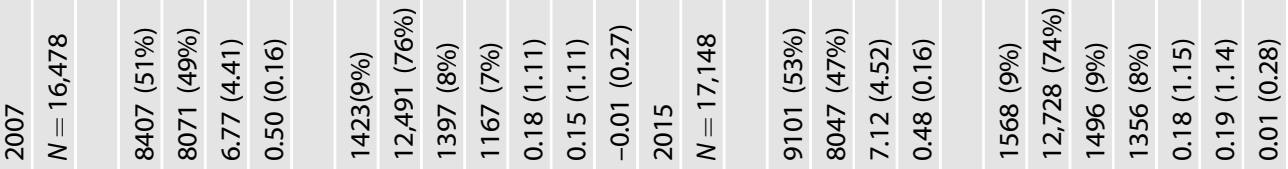

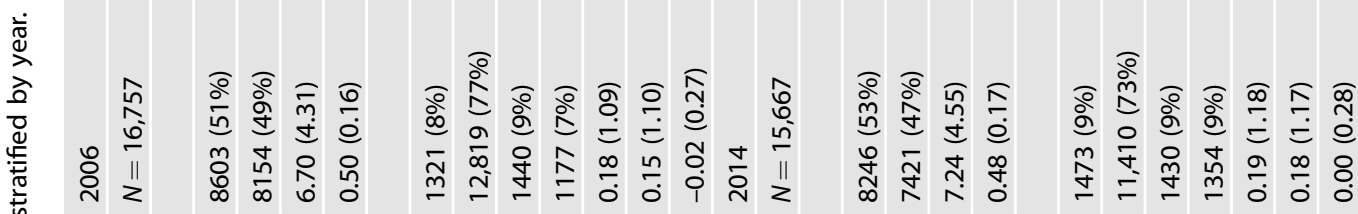

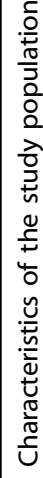

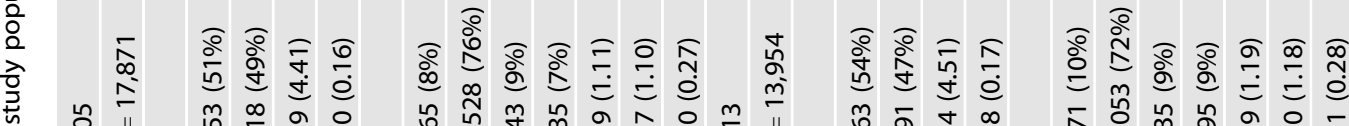

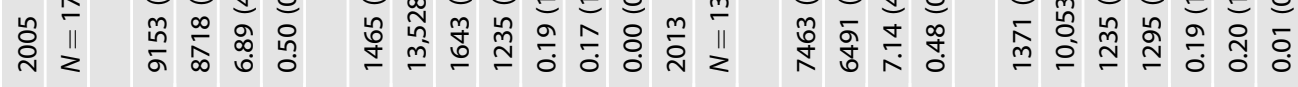

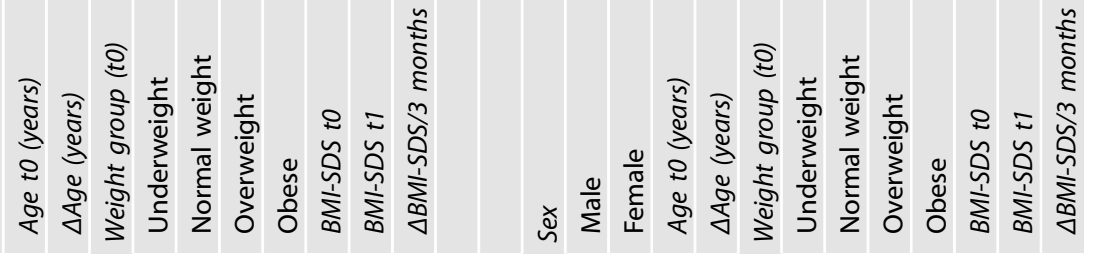




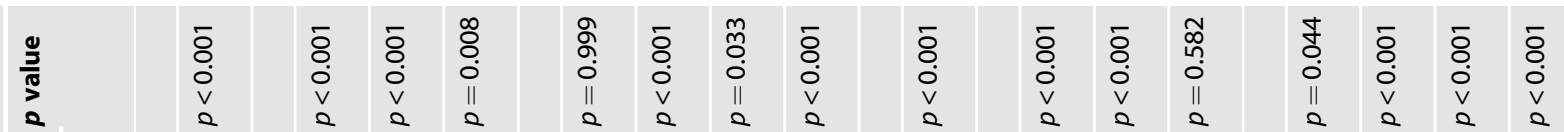

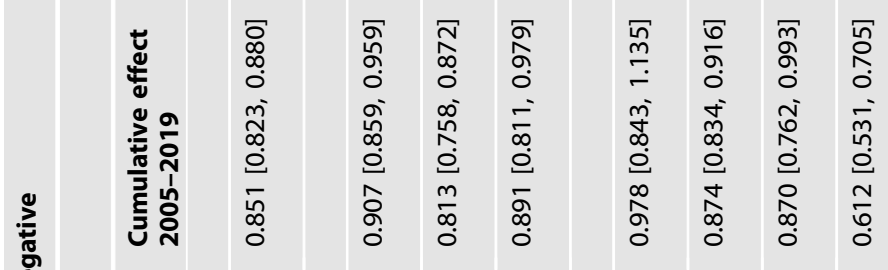

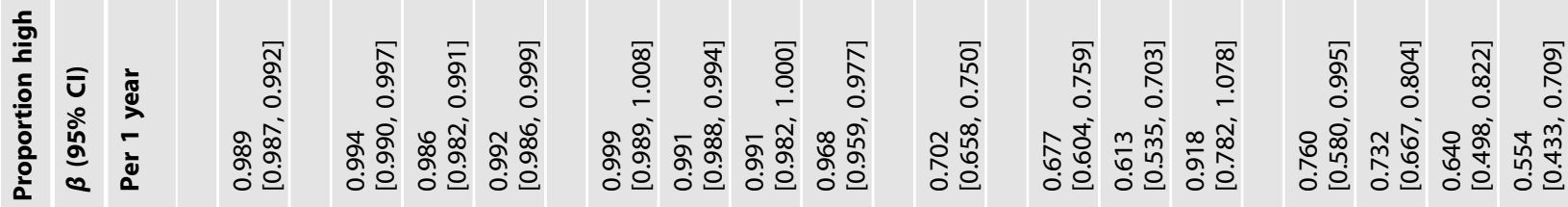

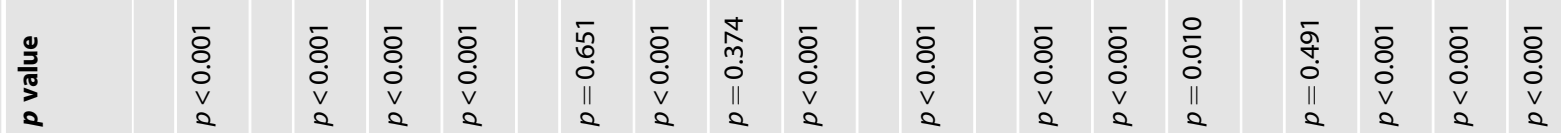

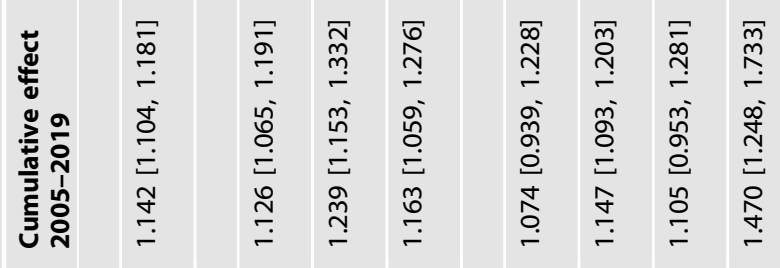

ญิ่

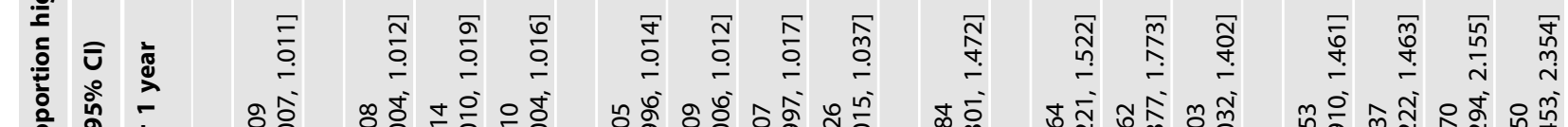

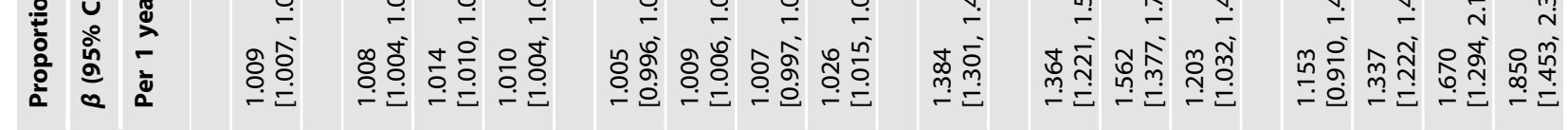

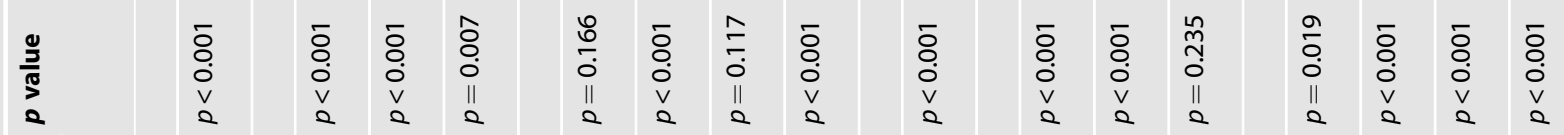

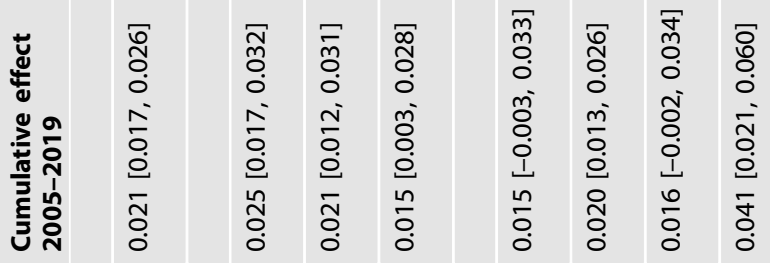

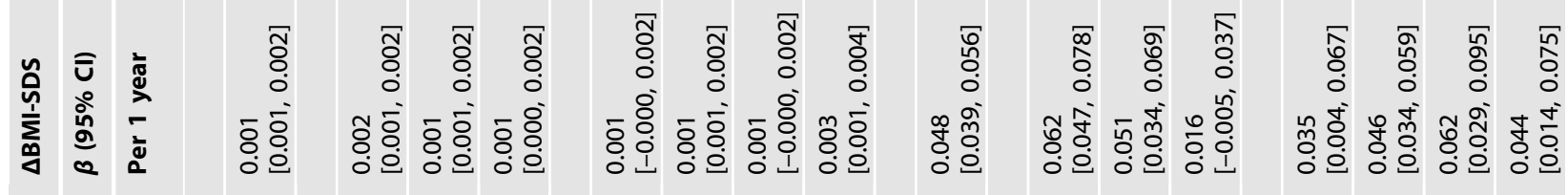

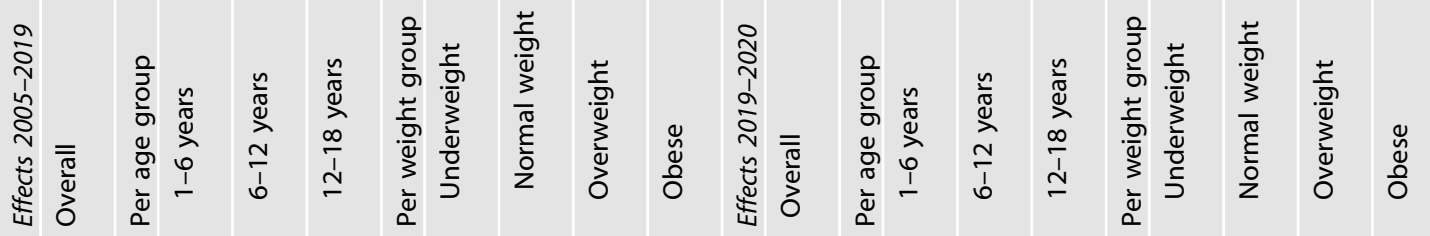




\section{Trends in the 3-month change of BMI-SDS}

Overall, there was a yearly increase of $\beta_{1 y}=0.0014(95 \% \mathrm{Cl}$ $0.0011-0.0017 ; p<0.001)$ in the 3 -month change in BMI-SDS between 2005 and 2019, i.e., the 3-month change in BMI-SDS increased between 2005 and 2019 by 0.02 SDS from -0.006 in 2005 to 0.013 in 2019. The increase was similar across the age groups but differed significantly across weight groups. Whereas the groups UW, NW, and OW showed marginally significant effects around $\beta_{1 y}=0.001$, a substantially higher effect was present in the OB group $\left(\beta_{1 y}=0.003,95 \% \mathrm{Cl} 0.001-0.004 ; p<0.001\right)$. From 2019 to 2020 , we found an increase of $\beta=0.048$ in the 3-month change in BMI-SDS (95\% Cl 0.039-0.056; $p<0.001)$-more than 30 times higher than the rate before 2020 . Therefore, in 2020, the resulting 3 -month change in BMI-SDS was 0.06. The increase was higher in younger children ( $1-6$ years: $\beta=0.062 ; 95 \% \mathrm{Cl} 0.047-0.078 ; p<$ $0.001 ; 6-12$ years: $\beta=0.051 ; 95 \% \mathrm{Cl} 0.034-0.069 ; p<0.001)$. In adolescents, the effect did not reach statistical significance. The trends are visualized in Figs. $1 \mathrm{~A}$ and $2 \mathrm{~A}$.

\section{Trends in high positive (HPC) and high negative (HPC) change in BMI-SDS}

Notably, from 2005 to 2019 , there was a positive trend $\left(\mathrm{OR}_{1 y}=\right.$ 1.01 per year; $95 \% \mathrm{Cl} 1.009-1.011 ; p<0.001)$ in the proportion of children with an HPC and a negative one $\left(\mathrm{OR}_{1 \mathrm{y}}=0.99\right.$ per year; $95 \% \mathrm{Cl} 0.987-0.992 ; p<0.001)$ in the proportion of children with an HNC. These effects accumulated to $\mathrm{OR}_{15 y}=$ $1.14(95 \% \mathrm{Cl} 1.10-1.18)$ and $\mathrm{OR}_{15 y}=0.85$ (95\% Cl 0.82-0.88), whereas we found no difference in the trend between age groups for HPC, the trend for HNC was stronger in 6- to 12-yearold children $\left(\mathrm{OR}_{15 \mathrm{y}}=0.81 ; 95 \% \mathrm{Cl} 0.76-0.87 ; p<0.001\right)$. Considering the weight status, both effects, HPC and HNC, were substantially stronger in the OB group (HPC: $\mathrm{OR}_{15 y}=1.47 ; 95 \%$ Cl 1.25-1.73; $p<0.001 ; \mathrm{HNC}: \mathrm{OR}_{15 \mathrm{y}}=0.61 ; 95 \% \mathrm{Cl} 0.53-0.71 ; p<$ 0.001 ), which is consistent with the higher increase in the 3-month change in BMI-SDS in this group. For HPC, the cumulative effects in UW, NW, and $\mathrm{OW}$ varied between $\mathrm{ORs}_{15 \mathrm{y}}$ of 1.07 and 1.15, reaching the level for significance only for NW. For HNC, we found also smaller but similar effects for NW $\left(\mathrm{OR}_{15 y}=0.87,95 \% \mathrm{Cl} 0.83-0.91 ; p<0.001\right)$ and $\mathrm{OW}\left(\mathrm{OR}_{15 y}=\right.$ $0.87 ; 95 \% \mathrm{Cl} 0.76-0.99 ; p=0.033)$. When looking at the respective percentages of children with HPC and HNC, we found that the percentages of children with HNC varied between $45 \%$ and $50 \%$ in the OW and OB weight group until 2008 and decreased to around 40\% in 2019. On the other hand, there was an increase of children with overweight or obesity showing HPC: from about $26 \%$ (OW)/22\% (OB) until 2008 to $29 \%$ $(\mathrm{OW}) / 28 \%(\mathrm{OB})$ in 2019 (pre-pandemic).

From 2019 to 2020, the increase in the proportion of children with HPC corresponds to an OR of 1.38 (95\% CI 1.30-1.47; $p<$ $0.001)$. As for the 3 -month change in BMI-SDS, the effect is more than 30 times as high as for the years before. A similar effect was observed for the proportion of children showing $\mathrm{HNC}(\mathrm{OR}=0.70 ; 95 \% \mathrm{Cl} 0.66-0.75 ; p<0.001)$. Both effects were stronger for higher weight status. Hence, the highest effects were found in the OB group. Here, the OR for HPC was $\mathrm{OR}_{\text {high_pos }}=1.85(95 \% \mathrm{Cl} 1.45-2.35 ; p<0.001)$, and for HNC, it was OR ${ }_{\text {high neg }}=0.55(95 \% \mathrm{Cl} 0.43-0.71 ; p<0.001)$. For OW, the respective effects were $\mathrm{OR}_{\text {high pos }}=1.67(95 \% \mathrm{Cl} 1.30-2.16 ; p<$ $0.001)$ and $\mathrm{OR}_{\text {high } \_ \text {neg }}=0.64(95 \% \mathrm{Cl} 0.50-0.82 ; p<0.001)$, and for NW, $\left.\mathrm{OR}_{\text {high } \operatorname{pos}}=1.34 ; 95 \% \mathrm{Cl} 1.22-1.46 ; p<0.001\right)$ and $\mathrm{OR}_{\text {high_neg }}=0.73(95 \% \mathrm{Cl} 0.67-0.80 ; p<0.001)$. For UW, only the proportion of children showing HNC changed significantly, with an $\mathrm{OR}_{\text {high_neg }}=0.76(95 \% \mathrm{Cl} \quad 0.58-0.99 ; p=0.044)$. Considering age, the effects were more pronounced in children and younger adolescents $\left(1-6\right.$ years: $O_{\text {high_pos }}=1.36 ; 95 \% \mathrm{Cl}$ $1.22-1.52 ; p<0.001$ and $\mathrm{OR}_{\text {high } \_ \text {neg }}=0.68 ; 95 \% \mathrm{Cl} 0.60-0.76$; $p<0.001 ; 6-12$ years: $\mathrm{OR}_{\text {high_pos }}=1.56 ; 95 \% \mathrm{Cl} 1.38-1.77$; $p<0.001$ and $\left.\mathrm{OR}_{\text {high } n \text { neg }}=0.61 ; 95 \% \mathrm{Cl} 0.54-0.70 ; p<0.001\right)$. In adolescents, only the effect for an HPC reached statistical significance $\left(\mathrm{OR}_{\text {high_pos }}=1.20 ; 95 \% \mathrm{Cl} 1.03-1.40 ; p=0.010\right)$.

Subsequently, during the first few months of the pandemic, the proportion of children with HNC shrunk by more than $10 \%$ and reached $33 \%$ and $26 \%$ in the $\mathrm{OW}$ and $\mathrm{OB}$ weight group, respectively. At the same time, the proportions of children with HPC rose by more than $10-41 \%$ (OW and OB), which is consistent with the higher pandemic change in BMI-SDS.

All effects (overall as well as stratified by age and weight group) are summarized in Table 2 and visualized in Figs. $1 B, C$ and 2B, C. For the interest of the reader, the prevalences of UW, NW, OW, and $\mathrm{OB}$ are given stratified by age and weight group in Supplementary Table 3.

\section{DISCUSSION}

This registry-based study found a small but stable positive trend in the 3-month change in BMI-SDS between 2005 and 2020, with an exceptional aggravation during the last year-the latter most likely attributable to COVID-19-induced measures. Our finding of an accelerated change in BMI-SDS between 2005 and 2019 is not contrary to studies reporting stabilizing or even downward trends of overweight and obesity prevalence $[29,30]$. Rather, we found the most pronounced dynamics within the already affected population. In general, the trend was positive for all age and weight groups and strongest in children already affected by overweight or obesity. Even if some subgroup effects did not reach statistical significance, this stable consistency is alarming: especially in children with obesity, we would expect some negative effects because of the statistical regression to the mean phenomenon, i.e., if we observe some extreme values (like BMISDS values in the range of obesity), we would expect a future value being less extreme and, therefore, nearer to the mean. The aggravation of childhood obesity becomes even more evident when we look at the proportions of children with HPC or HNC. The percentage of children with HNC fell from approximately 45-50\% (2005-2008) in the OW and OB weight group to around $40 \%$ in 2019, whereas the percentage of children with HPC rose from about 26\% (OW)/22\% (OB) to 29\% (OW)/28\% (OB) in 2019 (pre-pandemic).

The effects from 2019 to 2020 are even more alarming. Despite the short time interval of a few months, they surmounted the cumulative effects of the 15 years before: the percentage of children with HPC/HNC rose/dropped by more than $10 \%$ for children with overweight or obesity. Even though adolescents seem to be less severely affected, there is no reason for giving the all-clear: the obesity prevalence in this age group increased from 2005 to 2020 (pre-pandemic) from 10\% to 19\% (Supplementary Table 3). Older adolescents are the age group with the highest obesity prevalence. Here, it becomes evident that even a small increase can have large effects over time. The same effects were found in normal weight children but less pronounced. The already most affected population seems to be the most vulnerable, whether in terms of small long-term or short-term effects.

Our findings are in line with several studies on COVID-19-related weight changes in adults [9, 10] and children [31-34] and studies on weight gain in children associated with the economic crisis in 2007-2008 [17, 18, 35] or the great Fukushima earthquake 2011 $[19,36]$. Zheng et al. showed that the initial increase of BMI and obesity prevalence persisted or even aggravated at least two years after the earthquake. The effect was more pronounced if children also experienced a personal disaster like a stay in an evacuation center or the death of a family member [36]. Indeed, a Korean study in 226 pediatric patients of a growth clinic found a mean BMI-SDS change of approximately +0.22 SDS/year during the 
lockdown accompanied by higher LDL, triglyceride, uric acid, and total cholesterol values [37]. The change rate is comparable to our 3-month change in BMI-SDS of +0.06 SDS that corresponds to a yearly change of +0.24 SDS. Weaver et al. found an even greater BMI-SDS change of +0.34 SDS/year in 182 US-American elementary school children [33]. Wen et al. examined almost 20,000 Chinese preschoolers aged 3-5.5 years. They also found higher $\mathrm{BMI}$ change rates during the first pandemic lockdown period than during the two years before [31]. Brooks et al. analyzed BMI data from more than 45,000 6- to 17-year-old children and adolescents between September and December 2020 and compared the changes rates to pre-pandemic changes rates (2017 to March 2020). In line with our results, they found an excessive acceleration of BMI-SDS change in the younger children, with rates two times as high as before. Moreover, they also found children with overweight and obesity more severely affected than their normal weight peers [34]. In addition, several other studies reported a remarkable weight gain in children associated with COVID-related lockdown periods (Korea, $n=169$, pediatric patients [38]; US, $n=$ 29, elementary school children [39]; China, $n=445$, children aged 7-12 years [40]; China, $n=10,082$, students of high schools, colleges, and graduate schools aged $>16$ years [41]; Italy, $n=51$, adolescents with obesity aged 10-18 [32]; Greece $n=397$, children and adolescents aged 2-18 years [42]).

Although we have no information on the health-related behavior regarding our study population, a decrease in PA and an unfavorable change in dietary behavior seem to be the most likely explanation for the sudden and high change in weight trends. Germany was mildly to moderately affected during the first COVID-19 wave. However, in late March 2020, non-essential educational, cultural, and administrative facilities were closed. Only essential shops stayed open. Playgrounds and sports facilities were closed and cordoned off. Schools and nurseries stayed entirely closed until mid-May. Education was only possible through online platforms. From mid-May, a partial re-opening was allowed with restrictions (hygiene rules, distancing, wearing masks, strict separation of groups, etc., had to be secured). Most schools implemented a hybrid model of online and on-site lessons. The proportion of on-site classes was often less than $50 \%$. Besides, compulsory education was suspended until the end of the school year, i.e., parents could decide whether or not a child had to go to school. Nurseries were also re-opened in mid-May, but opening hours were often limited due to staff shortages (employees belonged to a risk group, childcare obligations, COVID-19-related quarantine) [43]. Children and adolescents were living through a time of rapid changes in their daily routines. For many, the days became less structured, which is known to increases the risk of obesogenic behaviors [44, 45]. And indeed, several studies showed an accelerated weight gain during the summer months compared to the school year and time in nurseries $[45,46]$, with higher effects in overweight than in normal weight children [47]. The mechanisms are not fully understood [45]. A COVID-19-related decrease in PA has already been shown [5-8, 48-50], often related to an increase of SB $[5,7,8,49,50]$. There are mixed results concerning dietary behavior $[5,50,51]$. Several studies reported higher consumption of fruits or vegetables [5, 42, 51-53], one lower [50]. There was also an increase in the consumption of unhealthy foods and sweets $[5,51]$. The latter might be tightly connected to increased snacking $[9,52,53]$ during the increased screen time $[4,54]$ or due to boredom [51]. This is in line with studies in adults, reporting an increase in food consumption because of increased snacking, due to boredom, and the increased availability of food during the COVID-19-induced confinement $[9,55]$. Other reasons for increased snacking in children might be changes in parental feeding behavior. Jansen et al. and Philippe et al. showed increased emotional and instrumental feeding practices in parents of 2- to 12-year-old children during COVID-19 [52, 56].

\section{Limitations}

Participation in the CrescNet registry is voluntary. We have no information of non-participants, neither of the number of nonparticipants nor the reasons for non-participation. Furthermore, we have no information on behavioral patterns like PA, sedentary time, eating behavior, or food consumption. Therefore, we cannot examine the associations between changes in weight gain pattern and possible reasons or other possible confounders, except age, sex, and initial weight group. We also cannot guarantee that the composition of the population did not change due to COVID-19 in regard to the unmeasured potential confounders (e.g., socioeconomic status, PA, nutritional behavior).

\section{CONCLUSION}

We found a small but stable positive trend in the 3-month change in BMI-SDS and in the proportion of children with a high positive weight change between 2005 and 2020. These trends were accompanied by a decrease in the proportion of children with a high negative weight change, both adding to the still-growing problem of childhood obesity. During the COVID-19 pandemic, these effects have increased by more than 30 times within the relatively short period. We hypothesize that these effects are caused by the COVID-19-induced changes in health-related behavior and may lead to a significant further aggravation of the childhood obesity pandemic.

\section{REFERENCES}

1. McElroy E, Patalay P, Moltrecht B, Shevlin M, Shum A, Creswell C, et al. Demographic and health factors associated with pandemic anxiety in the context of COVID-19. Br J Health Psychol. 2020;25:934-44.

2. Loades ME, Chatburn E, Higson-Sweeney N, Reynolds S, Shafran R, Brigden A, et al. Rapid systematic review: the impact of social isolation and loneliness on the mental health of children and adolescents in the context of COVID-19. J Am Acad Child Adolesc Psychiatry. 2020;59:1218-39.

3. Workman J. How much may COVID-19 school closures increase childhood obesity? Obesity (Silver Spring). 2020;28:1787.

4. Jia P. A changed research landscape of youth's obesogenic behaviours and environments in the post-COVID-19 era. Obes Rev. 2021;22 Suppl 1:e13162.

5. Pietrobelli A, Pecoraro L, Ferruzzi A, Heo M, Faith M, Zoller T, et al. Effects of COVID-19 lockdown on lifestyle behaviors in children with obesity living in Verona, Italy: a longitudinal study. Obesity (Silver Spring). 2020;28:1382-5.

6. Ruíz-Roso MB, de Carvalho Padilha P, Matilla-Escalante DC, Brun P, Ulloa N, Acevedo-Correa $D$, et al. Changes of physical activity and ultra-processed food consumption in adolescents from different countries during Covid-19 pandemic: an observational study. Nutrients. 2020;12:2289.

7. Dunton GF, Do B, Wang SD. Early effects of the COVID-19 pandemic on physical activity and sedentary behavior in children living in the U.S. BMC Public Health. 2020;20:1351.

8. Xiang M, Zhang Z, Kuwahara K. Impact of COVID-19 pandemic on children and adolescents' lifestyle behavior larger than expected. Prog Cardiovasc Dis. 2020;63:531-2.

9. Zachary Z, Brianna F, Brianna L, Garrett P, Jade W, Alyssa D, et al. Self-quarantine and weight gain related risk factors during the COVID-19 pandemic. Obes Res Clin Pract. 2020;14:210-6.

10. He M, Xian Y, Lv X, He J, Ren Y. Changes in body weight, physical activity, and lifestyle during the semi-lockdown period after the outbreak of COVID-19 in China: an online survey. Disaster Med Public Health Prep. 2021;15:e23-e28.

11. Geserick M, Vogel M, Gausche R, Lipek T, Spielau U, Keller E, et al. Acceleration of $\mathrm{BMI}$ in early childhood and risk of sustained obesity. $\mathrm{N}$ Engl J Med. 2018;379:1303-12.

12. Cuschieri S, Grech S. COVID-19: a one-way ticket to a global childhood obesity crisis? J Diabetes Metab Disord. 2020;19:2027-30.

13. Nogueira-de-Almeida CA, Del Ciampo LA, Ferraz IS, Del Ciampo IRL, Contini AA, Ued F, et al. COVID-19 and obesity in childhood and adolescence: a clinical review. J Pediatr (Rio J). 2020;96:546-58.

14. Malhotra S, Sivasubramanian R, Singhal V. Adult obesity and its complications: a pediatric disease? Curr Opin Endocrinol Diabetes Obes. 2021;28:46-54.

15. Fernandes DM, Oliveira CR, Guerguis S, Eisenberg R, Choi J, Kim M, et al. Severe acute respiratory syndrome coronavirus 2 clinical syndromes and predictors of 
disease severity in hospitalized children and youth. J Pediatr. 2021;230:223-31. e10. https://doi.org/10.1016/j.jpeds.2020.11.016.

16. An R. Projecting the impact of the coronavirus disease-2019 pandemic on childhood obesity in the United States: a microsimulation model. J Sport Health Sci. 2020;9:302-12.

17. Ueda $\mathrm{P}$, Kondo N, Fujiwara T. The global economic crisis, household income and pre-adolescent overweight and underweight: a nationwide birth cohort study in Japan. Int J Obes (Lond). 2015;39:1414-20.

18. Rajmil L, Medina-Bustos A, Fernández de Sanmamed M-J, Mompart-Penina A. Impact of the economic crisis on children's health in Catalonia: a before-after approach. BMJ Open. 2013;3:e003286.

19. Zheng W, Yokomichi $H$, Matsubara $H$, Ishikuro $M$, Kikuya $M$, Isojima $T$, et al. Longitudinal changes in body mass index of children affected by the Great East Japan Earthquake. Int J Obes (Lond). 2017;41:606-12.

20. Agarwal DV, Sunitha BK. COVID - 19: current pandemic and its societal impact. Int J Adv Sci. 2020;29:432-9.

21. Kiess W, Gausche R, Keller A, Burmeister J, Willgerodt H, Keller E. Computerguided, population-based screening system for growth disorders (CrescNet) and on-line generation of normative data for growth and development. Horm Res. 2001;56 Suppl 1:59-66.

22. Vogel M, Beger C, Gausche R, Jurkutat A, Pfaeffle R, Körner A, et al. COVID-19 pandemic and families' utilization of well-child clinics and pediatric practices attendance in Germany. BMC Res Notes. 2021;14:140.

23. Brown CL, Montez K, Amati JB, Simeonsson K, Townsend JD, Orr CJ, et al. Impact of COVID-19 on pediatric primary care visits at four academic institutions in the Carolinas. Int J Environ Res Public Health. 2021;18:5734.

24. Jansen DEMC, Illy KE. Delayed presentation to regular Dutch paediatric care in COVID-19 times: a national survey. BMJ Paediatrics Open. 2020;4:e000834.

25. Wabitsch M, Moss A. Evidence-based (S3) guideline of the Working Group on Childhood and Adolescent Obesity (AGA) of the German Obesity Society (DAG) and the German Society of Pediatrics and Adolescent Medicine (DGKJ). 2019. https://www.awmf.org/leitlinien/detail/ll/050-002.html. Accessed Sep 2021.

26. Kromeyer-Hauschild K, Wabitsch M, Kunze D, Geller F, Geiss HC, Hesse V, et al. Percentiles of body mass index in children and adolescents evaluated from different regional German studies. Monatsschrift fur Kinderheilkunde. 2001;149:807-18.

27. Bretz F, Hothorn T, Westfall P. Multiple comparisons using R. 1st ed. Boca Raton, FL: Chapman and Hall/CRC; 2010.

28. R Core Team. R: a language and environment for statistical computing. Vienna, Austria; 2019. https://www.R-project.org/.

29. Garrido-Miguel M, Cavero-Redondo I, Álvarez-Bueno C, Rodríguez-Artalejo F, Moreno LA, Ruiz JR, et al. Prevalence and trends of overweight and obesity in European children from 1999 to 2016. JAMA Pediatr. 2019;173:e192430.

30. Kess A, Spielau U, Beger C, Gausche R, Vogel M, Lipek T, et al. Further stabilization and even decrease in the prevalence rates of overweight and obesity in German children and adolescents from 2005 to 2015: a cross-sectional and trend analysis. Public Health Nutr. 2017;20:3075-83.

31. Wen J, Zhu L, Ji C. Changes in weight and height among Chinese preschool children during COVID-19 school closures. Int J Obes. 2021;45:2269-73.

32. Maltoni G, Zioutas M, Deiana G, Biserni GB, Pession A, Zucchini S. Gender differences in weight gain during lockdown due to COVID-19 pandemic in adolescents with obesity. Nutr Metab Cardiovasc Dis. 2021;31:2181-5.

33. Weaver RG, Hunt ET, Armstrong B, Beets MW, Brazendale L, Turner-McGrievy G, et al. COVID-19 leads to accelerated increases in children's BMI z-score gain: an interrupted time-series study. Am J Prev Med. 2021;61:e161-e169.

34. Brooks CG, Spencer JR, Sprafka JM, Roehl KA, Ma J, Londhe AA, et al. Pediatric BMI changes during COVID-19 pandemic: an electronic health record-based retrospective cohort study. EClinicalMedicine. 2021;38:101026.

35. Norte A, Sospedra I, Ortíz-Moncada R. Influence of economic crisis on dietary quality and obesity rates. Int J Food Sci Nutr. 2019;70:232-9.

36. Yokomichi $H$, Zheng W, Matsubara $H$, Ishikuro $M$, Kikuya $M$, Isojima $T$, et al. Impact of the great east Japan earthquake on the body mass index of preschool children: a nationwide nursery school survey. BMJ Open. 2016;6:e010978.

37. Kang HM, Jeong DC, Suh BK, Ahn MB. The impact of the coronavirus disease2019 pandemic on childhood obesity and vitamin D status. J Korean Med Sci. 2021;36:e21.

38. Han J-A, Chung Y-E, Chung I-H, Hong Y-H, Chung S. Impact of the COVID-19 pandemic on seasonal variations in childhood and adolescent growth: experience of pediatric endocrine clinics. Children. 2021;8:404.

39. Brazendale K, Garcia J, Hunt ET, Blankenship M, Eisenstein D, Leon A. Preliminary evidence of children's weight gain from 5 months of home quarantine during the
COVID-19 pandemic. Am J Lifestyle Med. 2021:15598276211006656. https://doi. org/10.1177/15598276211006657.

40. Qiu N, He H, Qiao L, Ding Y, Ji S, Guo X, et al. Sex differences in changes in BMI and blood pressure in Chinese school-aged children during the COVID-19 quarantine. Int J Obes. 2021;45:2132-6.

41. Jia P, Zhang L, Yu W, Yu B, Liu M, Zhang D, et al. Impact of COVID-19 lockdown on activity patterns and weight status among youths in China: the COVID-19 Impact on Lifestyle Change Survey (COINLICS). Int J Obes. 2021;45:695-9.

42. Androutsos O, Perperidi M, Georgiou C, Chouliaras G. Lifestyle changes and determinants of children's and adolescents' body weight increase during the first COVID-19 lockdown in Greece: the COV-EAT study. Nutrients. 2021;13:930.

43. Freestate of Saxony. Archive of expired official announcements. https://www coronavirus.sachsen.de/archiv-der-abgelaufenen-amtlichen-bekanntmachungen7295.html. Accessed Jan 2021.

44. Brazendale K, Beets MW, Weaver RG, Pate RR, Turner-McGrievy GM, Kaczynski AT, et al. Understanding differences between summer vs. school obesogenic behaviors of children: the structured days hypothesis. Int J Behav Nutr Phys Act. 2017;14:100.

45. von Hippel PT, Workman J. From kindergarten through second grade, U.S. children's obesity prevalence grows only during summer vacations. Obesity (Silver Spring). 2016;24:2296-2300.

46. Moreno JP, Johnston CA, Chen T-A, O'Connor TA, Hughes SO, Baranowski J, et al Seasonal variability in weight change during elementary school. Obesity (Silver Spring). 2015;23:422-8

47. Hippel P, von, Powell B, Downey D, Rowland N. The effect of school on overweight in childhood: gain in body mass index during the school year and during summer vacation. Am J Public Health. 2007;97:696-702.

48. Tison GH, Avram R, Kuhar P, Abreau S, Marcus GM, Pletcher MJ, et al. Worldwide effect of COVID-19 on physical activity: a descriptive study. Ann Intern Med. 2020;173:767-70.

49. Moore SA, Faulkner G, Rhodes RE, Brussoni M, Chulak-Bozzer T, Ferguson LJ, et al. Impact of the COVID-19 virus outbreak on movement and play behaviours of Canadian children and youth: a national survey. Int J Behav Nutr Phys Act. 2020;17:85.

50. López-Bueno R, López-Sánchez GF, Casajús JA, Calatayud J, Gil-Salmerón A Grabovac I, et al. Health-related behaviors among school-aged children and adolescents during the spanish Covid-19 confinement. Front Pediatr. 2020;8:573.

51. Ruiz-Roso MB, de Carvalho Padilha $\mathrm{P}$, Mantilla-Escalante DC, Ulloa $\mathrm{N}$ Brun $\mathrm{P}$, Acevedo-Correa $\mathrm{D}$, et al. Covid-19 confinement and changes of adolescent's dietary trends in Italy, Spain, Chile, Colombia and Brazil. Nutrients. 2020;12:1807.

52. Philippe K, Chabanet C, Issanchou S, Monnery-Patris S. Child eating behaviors, parental feeding practices and food shopping motivations during the COVID-19 lockdown in France: (How) did they change? Appetite. 2021;161:105132.

53. Sidor A, Rzymski P. Dietary choices and habits during COVID-19 lockdown: experience from Poland. Nutrients. 2020;12:1657. https://doi.org/10.3390/ nu12061657.

54. Nagata JM, Abdel Magid HS, Pettee Gabriel K. Screen time for children and adolescents during the coronavirus disease 2019 pandemic. Obesity (Silver Spring). 2020;28:1582-3.

55. Ammar A, Brach M, Trabelsi K, Chtourou H, Boukhris O, Masmoudi L, et al. Effects of COVID-19 home confinement on eating behaviour and physical activity: results of the ECLB-COVID19 international online survey. Nutrients. 2020;12:1583.

56. Jansen E, Thapaliya G, Aghababian A, Sadler J, Smith K, Carnell S. Parental stress, food parenting practices and child snack intake during the COVID-19 pandemic. Appetite. 2021;161:105119.

\section{ACKNOWLEDGEMENTS}

We thank all participating pediatricians, their patients, and the patients' families. This work was supported by the Free State of Saxony as per the budget approved by the state parliament (GeoEtiology), by the Regional Development Fund (LIFE Forschungszentrum, LIFE Child), and by means of the Free State of Saxony within the framework of the excellence initiative, and the Collaborative Research Center "Obesity Mechanisms" (IFB AdipositasDiseases). The CrescNet registry infrastructure was supported by grants from Hexal AG Germany, NovoNordisk Pharma GmbH, Merck Serono Pharma GmbH, Lilly Deutschland $\mathrm{GmbH}$, Pfizer Pharma $\mathrm{GmbH}$, and Ipsen Pharma GmbH (ClinicalTrials.gov NCT03072537). 


\section{AUTHOR CONTRIBUTIONS}

Conceptualization: RP, RG, MV, and WK; methodology: EK, CM, and MV; software: $C M$ and $\mathrm{CB}$; formal analysis: $M V$ and $M G$; resources: $W K$ and $R P$; data preparation and curation: $C B$ and RG; writing - original draft preparation: MV; review and discussion of the manuscript: all coauthors; revision process: all authors; writing —editing: MV and TP; visualizations: MV and MG; project administration: RG; and funding acquisition: EK, WK, RG, and RP. All authors have read and agreed to the published version of the manuscript.

\section{FUNDING}

Open Access funding enabled and organized by Projekt DEAL.

\section{COMPETING INTERESTS}

The authors declare no competing interests.

\section{ADDITIONAL INFORMATION}

Supplementary information The online version contains supplementary material available at https://doi.org/10.1038/s41366-021-00968-2.

Correspondence and requests for materials should be addressed to Mandy Vogel.
Reprints and permission information is available at http://www.nature.com/ reprints

Publisher's note Springer Nature remains neutral with regard to jurisdictional claims in published maps and institutional affiliations.

Open Access This article is licensed under a Creative Commons Attribution 4.0 International License, which permits use, sharing, adaptation, distribution and reproduction in any medium or format, as long as you give appropriate credit to the original author(s) and the source, provide a link to the Creative Commons license, and indicate if changes were made. The images or other third party material in this article are included in the article's Creative Commons license, unless indicated otherwise in a credit line to the material. If material is not included in the article's Creative Commons license and your intended use is not permitted by statutory regulation or exceeds the permitted use, you will need to obtain permission directly from the copyright holder. To view a copy of this license, visit http://creativecommons. org/licenses/by/4.0/.

(c) The Author(s) 2021 